\title{
How do low/high height and weight variation affect upper limb movements during manual material handling of industrial boxes?
}

\author{
Como a variação de altura e massa da carga afetam os movimentos do membro \\ superior durante o manuseio de caixas industriais?
}

Ana B. Oliveira, Luciana C. C. B. Silva, Helenice J. C. G. Coury

\begin{abstract}
Objectives: To evaluate the effect of surface height and load weight on upper limb movements and electromyographic (EMG) recordings during manual handling performed by both experienced and inexperienced lifter subjects. Methods: Sixteen experienced and sixteen inexperienced lifters handled a box (both 7 and $15 \mathrm{~kg}$ ) from an intermediate height (waist level) to either a high or low surface. Electromyography and video images were recorded during the tasks. The $10^{\text {th }}, 50^{\text {th }}$ and $90^{\text {th }}$ percentiles were calculated for the deltoid and biceps muscles, shoulder flexion, shoulder abduction, and elbow flexion movements. Groups, right/left sides, weights and heights were compared. There were no differences between either groups or sides. Results: Weight and height variations affected EMG and posture, although weight had more impact on EMG. Shoulder abduction and flexion movements higher than $60^{\circ}$ occurred, particularly for the higher surface. Shoulder flexion was also higher when the box was moved to the low height. This study provides new evidence as shoulder postures during boxes handling on low surfaces had not previously been evaluated. Conclusions: The high demand of upper limb in manual material handling tasks is clear, particularly for the shoulder. This knowledge can be used by physical therapists to plan better rehabilitation programs for manual material handling-related disorders, particularly focusing on return to work.
\end{abstract}

Keywords: biomechanics; environment design; weight lifting; cumulative trauma disorders; physical therapy.

\section{Resumo}

Objetivos: Avaliar o efeito da altura de superfície e massa da carga nos movimentos e na atividade eletromiográfica (EMG) dos membros superiores durante o manuseio de carga realizado por sujeitos experientes e inexperientes. Métodos: Dezesseis sujeitos experientes e 16 inexperientes manusearam uma caixa $(7$ e $15 \mathrm{~kg}$ ) de uma superfície com altura intermediária para uma superfície alta e/ou baixa. Durante as tarefas, foram registradas imagens de vídeo e EMG. Os dados foram processados para obtenção dos percentis 10, 50 e 90 referentes à EMG dos músculos deltoide e bíceps e aos movimentos de flexão e abdução do ombro e flexão do cotovelo. Foram comparados os grupos, lados (direito/esquerdo), massas e altura de manuseio. Resultados: Não foram encontradas diferenças significantes entre os grupos ou lados. As variações de massa e altura de manuseio afetaram a EMG e postura, embora a massa da caixa tenha tido mais impacto sobre a EMG. Os movimentos de abdução e flexão do ombro ocorreram acima de $60^{\circ}$, particularmente no manuseio para a superfície alta. A amplitude de flexão de ombro também foi alta quando a caixa foi movida para a superfície baixa. Esse resultado consiste em uma nova evidência, já que posturas do ombro durante o manuseio de carga em superfícies baixas não tinham sido investigadas. Conclusões: A alta demanda do membro superior em tarefas de manuseio de carga é clara, particularmente do ombro. Esse conhecimento pode ser usado por fisioterapeutas para um melhor planejamento da reabilitação de lesões relacionadas ao manuseio de cargas, visando o retorno ao trabalho.

Palavras-chave: biomecânica; planejamento ambiental; levantamento de peso; transtornos traumáticos cumulativos; fisioterapia.

Received: 07/16/2011 - Revised: 07/18/2011 - Accepted: 07/19/2011

Physical Therapy Department, Universidade Federal de São Carlos, São Carlos, SP, Brazil

Correspondence to: Ana Beatriz Oliveira, Universidade Federal de São Carlos, Departamento de Fisioterapia, Rodovia Washington Luis, KM 235, CEP 13565-905, São Carlos, SP, Brazil, e-mail: biaoliveira@gmail.com; biaoliveira@ufscar.br 


\section{Introduction : :}

Manual material handling (MMH) activities are performed in a wide variety of occupational settings. The relationship between MMH and work-related musculoskeletal disorders (WRMSDs) is well established in the literature ${ }^{1-4}$. In general, 25 to $36 \%$ of reported WRMSDs are related to MMH activities ${ }^{3,5,6}$. The part of the body most affected is the lumbar spine, with a prevalence ranging from 50 to $70 \%^{3,4,7}$. Epidemiological studies have also reported high prevalence of WRMSDs in other body sites. The second most affected region is the shoulder, with a prevalence of MMH-related to WRMSDs ranging from 38 to $60 \% \%^{3,47,7}$.

In order to reduce the occurrence and to prevent new episodes of WRMSDs associated with MMH activities, a better understanding of musculoskeletal loads and the effects of task parameters during this type of activity is crucial. This knowledge is valuable for the ergonomics team (physical therapists, ergonomic designers and engineers), to support a better job design. The strategies of MMH activities have been studied through biomechanical and subjective approaches ${ }^{9,10,11}$. While the spinal load during several types of MMH activities has been well studied ${ }^{12-15}$, the upper limb load still remains neglected. The available literature can provide relevant information on upper limb load, however the studies are mainly focused on light and repetitive loads, which is not applicable when evaluating the musculoskeletal load during boxes handling. Therefore, more studies are needed in order to provide a better understanding about the influence of physical aspects of the occupational settings on upper limb workload during heavy handling.

Habes, Carlson and Badger ${ }^{16}$ studied the effect of destination height, load weight and reach on shoulder and lumbar spine muscle fatigue during a repetitive lifting task. They observed that the three factors (height, weight, and reach) have affected the electromyographic parameters studied. Nielsen, Andersen and Jørgensen ${ }^{17}$ assessed shoulder and lower back muscular loads and evaluated the amplitude probability distribution function (APDF) of surface electromyograms (EMGs) during lifting tasks using $10 \mathrm{~kg}$ boxes at different heights and frequencies. They found differences in muscular load according to height changes and frequency variation. Davis and Marras ${ }^{18}$ evaluated the influence of lift origin and destination on low back response. The three-dimensional spinal load was influenced by the origin and destination height. The authors acknowledged the importance of studying workplace spatial layout and biomechanical response during lifting. Hoozemans et al. ${ }^{14}$ have also studied the effect of lifting height and mass in low back load and reported that both height and mass have an effect on low back load. The available literature indicates that both handling height and load weight have an important role in musculoskeletal loads during MMH activities. However, all these studies have evaluated upper limb load during handling at or above waist height, when, it is known that occupational settings also involve heights below the waist level. Moreover, the handling of boxes has not been explored so far.

Another important factor that can influence the musculoskeletal load during $\mathrm{MMH}$ is the subjects' previous experience of load handling. According to interesting studies on back load by Gagnon ${ }^{19}$ and a recent paper published by Chen, Lee and $\mathrm{Chen}^{20}$, the strategy used by expert workers in performing $\mathrm{MMH}$ activities has safety potential. In general, they present strategies related to load maneuvers and footwork that differ from those of novice workers. Such strategies can reduce back loadings, back asymmetries and mechanical work requirements and, for these reasons, they can generate different profiles of musculoskeletal loads.

Therefore, when planning or redesigning MMH activities and workplaces, certain variables should be controlled in order to reduce musculoskeletal load for not only low back but also shoulder and upper limbs. With regards to biomechanical demand of upper limb in $\mathrm{MMH}$ activities, little information is available from the literature, particularly in relation to real or simulated occupational settings and taking into account the subject's experience. Besides contributing to the prevention WRMSDs, this knowledge can give to physical therapists a better understanding on the upper limb demand in MMH tasks. They can use this knowledge to plan better rehabilitation programs for $\mathrm{MMH}-$ related disorders, particularly focusing on return to work.

Assuming that workplace spatial layout, object weight and previous experience in handling might influence shoulder load, the objective of this study was to evaluate the effect of height and weight changes on the muscular activity and postures of upper limb joints during manual handling performed by experienced and inexperienced subjects.

\section{Methods : :}

\section{Subjects}

Male subjects with and without occupational load-handling experience were recruited. The inclusion criteria were that the subjects should not present musculoskeletal symptoms or disorders, general illnesses, range of motion deficits, apparent postural deviations or balance problems. The sample size was calculated using SigmaPlot (11.0, Systat Software, Inc), and considering the outcome shoulder abduction motion and the differences between experienced and inexperienced subjects ${ }^{21}$. The expected standard deviation of the difference for the abduction movement was set at $14.5^{\circ}$, based on a pilot study carried out with inexperienced subjects. The expected difference in means 
was set at $15^{\circ}$, considering that such difference would be biomechanically relevant. The alpha and beta level were set at 0.05 and 0.20 , respectively. The results showed a sample size of minimum fifteen subjects per group.

Thirty-two subjects, with a mean age of 22.6 ( $\mathrm{SD}=4.3)$ years, a mean height of 1.69 ( $\mathrm{SD}=0.04$ ) meters and a mean of weight 68.3 $(\mathrm{SD}=8.7) \mathrm{kg}$ were recruited for this study. Sixteen participants were experienced lifters (i.e. with at least 6 months of experience) and 16 were inexperienced (students, without professional manual box-handling experience). The experienced lifters were used to handle boxes of different weights (up to $20 \mathrm{~kg}$ ) and sizes in several conditions (palletizing and depalletizing; unloading trucks; filling shelves). All participants signed an informed consent form previously approved by the local ethics committee of the Universidade Federal de São Carlos (UFSCar), São Carlos, SP, Brazil (Approval 059/04).

\section{Procedures}

The participants handled a box (weighing either 7 or $15 \mathrm{~kg}$ ) from one shelf (intermediate shelf - IS - $102.5 \mathrm{~cm}$, about waist level) to either a higher shelf (high shelf - HS - $142.5 \mathrm{~cm}$ ) or lower shelf (low shelf - LS - $62.5 \mathrm{~cm}$ ). The weight of the box was determined after observing $\mathrm{MMH}$ tasks in a medium-sized industry (i.e. 1800 workers). Seventy percent of the observed tasks were performed involving boxes weighting from 7 to $15 \mathrm{~kg}$.

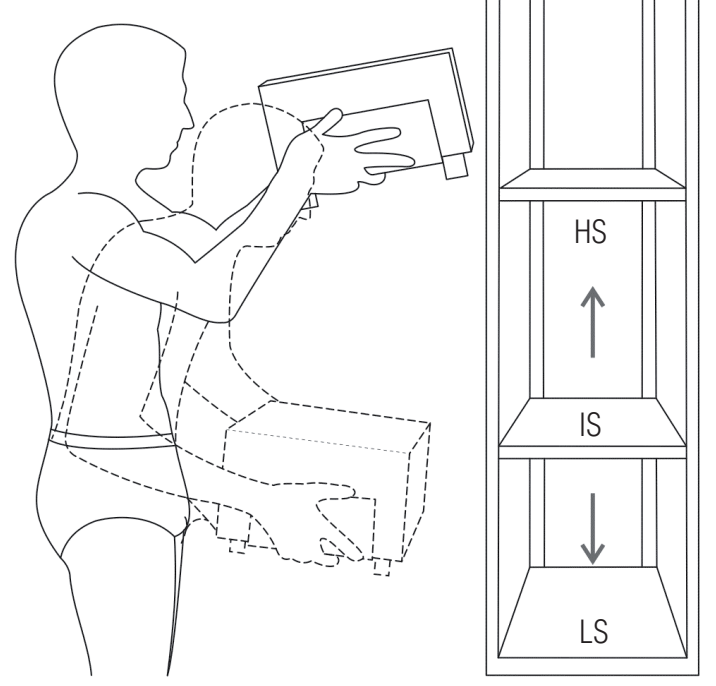

Figure 1. Layout of the manual handling tasks performed by the subjects. Full line indicates MMH from the intermediate shelf to the high shelf (IS $\rightarrow \mathrm{HS}$ ) and dotted line indicates MMH from the intermediate shelf to the low shelf (IS $\rightarrow \mathrm{LS}$ ).
Data relating to all four conditions (two box weights and two shelf heights) were recorded (see Figure 1). The participants always picked up the box from the IS and placed it on a predetermined shelf. No specific instructions were provided, either on postures or how to grasp the box. The shelf's height and weight of the box order were randomized. Before lifting the box, the subjects were provided with information about the initial and final positions of the box, and when to perform the task. Participants were not allowed to practice handling the boxes before starting the experiment. For each trial, simultaneous recordings of force applied on the box surfaces, electromyography (EMG) and video images were recorded.

\section{Force recordings}

A steel box built especially for the evaluation of manual handling tasks ${ }^{22}$ was used in this study. The box measured $300 \mathrm{~mm}$ in length x $300 \mathrm{~mm}$ in width $\mathrm{x} 180 \mathrm{~mm}$ in height and was built with four load cells internally and bilaterally fixed at the lateral surfaces and the bottom of the box, allowing the record (in kgf) of any force applied on these different parts of the box. Each load cell was connected to the DataLink acquisition unit (Biometrics Ltd, Gwent, UK). Data were sampled at $100 \mathrm{~Hz}$ and processed to establish the start and the end of each handling.

\section{Electromyography}

Surface EMGs were recorded bilaterally from both biceps and the middle fibers ( from the lateral margin and upper surface of the acromion) of deltoid muscles. Active single differential surface electrodes (Model \#DE-2.1, DelSys ${ }^{\circledR}$, Boston, USA) with a detection geometry consisting of two parallel silver bars $\left(1 \mathrm{~mm}^{2} \mathrm{x} 1 \mathrm{~cm}\right)$ separated by $1 \mathrm{~cm}$ were attached to the skin using a double-sided interface (DelSys ${ }^{\circledR}$ ). The electrode characteristics were: commonmode rejection ratio $(\mathrm{CMRR})>80 \mathrm{~dB}$; input impedance $>10 \Omega^{15}$ in parallel, with $0.2 \mathrm{pF}$; voltage gain of 10 ; and noise of $1.2 \mu \mathrm{V}$ (RMS). They were placed on the greatest bulge of the deltoid muscle, along the line between the acromion and the lateral epicondyle of the humerus; and on the biceps along the line between the medial acromion and the cubital fossa at one third of the distance from the cubital fossa. The reference electrode was placed on the left hand. Before attaching the electrodes, the skin was shaved and rubbed with alcohol over the appropriate areas. The electrode positioning and attachment were defined according to SENIAM recommendations ${ }^{23}$. The signals were further conditioned by the main amplifier (Bagnoli-8 EMG System, DelSys ${ }^{\circledR}$ ), which provided a gain of 1000, bandwidth $20-450 \mathrm{~Hz}$ and noise of $1.2 \mu \mathrm{V}$ (RMS). The data were sampled at a rate of $2000 \mathrm{~Hz}$ using a PC workstation with a 16-bit A/D card (PCI-6034E, National Instruments Corporation, Austin, USA) and EMGworks ${ }^{\circledR}$ software (version 3.0, DelSys ${ }^{\circledR}$ ). 


\section{Video recordings}

During the experiment, the subject's movements in the sagittal plane (right view) and frontal plane (posterior view) were recorded at $50 \mathrm{~Hz}$ using two digital cameras (GR-DV 1800, JVC). The cameras were placed perpendicularly to each other, $1.5 \mathrm{~m}$ above the floor level. Passive markers were attached to the subject's body at the following positions: on the shoulder at the posterior face of the acromion (right and left); on the elbow at the lateral epicondyle (right and left); on the wrist at the ulnar styloid process (right); and on the hip at the greater trochanter (right), according to the model of Okunribido and Haslegrave ${ }^{24}$. These markers were used to reconstruct right and left shoulder abduction, right shoulder flexion and right elbow flexion.

\section{Data analysis}

Force, EMG and video recordings were collected throughout the tests, but only the handling phase was analyzed. The handling phase was defined as the time during which the subject's hands were in contact with the box. The start and end of each handling period were established using force recordings. The analysis was performed using MatLab ${ }^{\circledR}$ software (version 7.0.1, MathWorks Inc., Natick, USA). The start was defined as the moment when the sum of force applied on the right and left bottom of the box reached $3 \mathrm{~N}$. The end was established as the moment when this sum decreased to less than $3 \mathrm{~N}$. These time-points were used to select the EMG and video records for the handling phase.

The kinematic data were digitized, filtered and reconstructed using the Ariel Performance Analysis System software (APAS ${ }^{\circledR}$, Ariel Dynamics, Inc., Trabuco Canyon, USA). Data were low-pass filtered at $5 \mathrm{~Hz}$ using a digital filter algorithm. The reconstruction of real coordinates was performed using the direct linear transformation (DLT) procedure. Shoulder abduction (SA), flexion (SF) and elbow flexion (EF) were calculated with the angles defined as shown in Figure 2, and stored as ASCII files. The accuracy of the movement reconstruction was tested and recorded at $2.1^{\circ}$ for SA (y-z plane), and $1.9^{\circ}$ for SF and EF (y-x plane).

The EMG data were processed using MatLab ${ }^{\circledR}$ software (version 7.0.1, MathWorks Inc., Natick, USA). All signals were band-pass filtered using a fourth-order zero-lag Butterworth filter at $20-400 \mathrm{~Hz}$, and were subsequently full-wave rectified and low-pass filtered at $5 \mathrm{~Hz}$ to obtain the linear envelope ${ }^{25}$. The signals were then selected using force recording, as described above, and were normalized to one specific handling - 'reference handling', which was performed with the same box, but weighting $11 \mathrm{~kg}$. The box was transferred from the intermediate to the high shelf. This reference contraction was chosen for the normalization procedure since it showed better results for inter-test comparison in relation to the mean value.
In addition, recent literature supports the use of dynamic contractions as reference for EMG normalization ${ }^{26}$.

An Amplitude Probability Distribution Function (APDF) was calculated for both the EMG and the kinematic data. According to Jonsson ${ }^{27}$, probability levels of 10,50 and $90 \%$ represent the static, median, and peak muscular load, respectively. The APDF method is a widely applied procedure for describing occupational load ${ }^{28,29}$ for both EMG and movement recordings ${ }^{30-33}$. The use of APDF analysis was more suitable particularly due to the short duration of each $\mathrm{MMH}$, as it can provide more detailed information than the analysis of time average.

In order to perform qualitative analysis and to compare possible patterns among the subjects, the linear envelope of each raw EMG signal was normalized for each condition in time from $0 \%$ to $100 \%$ in steps of $1 \%$. The same procedure was performed for shoulder flexion and abduction, and for elbow flexion angles.

\section{Statistics}

All data were tested for normality through Shapiro Wilk's W test. Accordingly, nonparametric tests were applied. The MannWhitney test was used to detect differences between the experienced and inexperienced subjects. The Wilcoxon matched-pairs test was applied to test for the differences between the right and left sides, between surfaces (low versus high), and between weights ( 7 versus $15 \mathrm{~kg}$ ). An alpha level of 0.05 was used for all statistic tests, which were performed using the Statistica ${ }^{\circledR}$ software (version 7, StatSoft, Inc., Tulsa, USA).

\section{Results $: \because$.}

The EMG and the movement data collected from the experienced and inexperienced lifters presented no statistically significant differences, and therefore the two groups have been

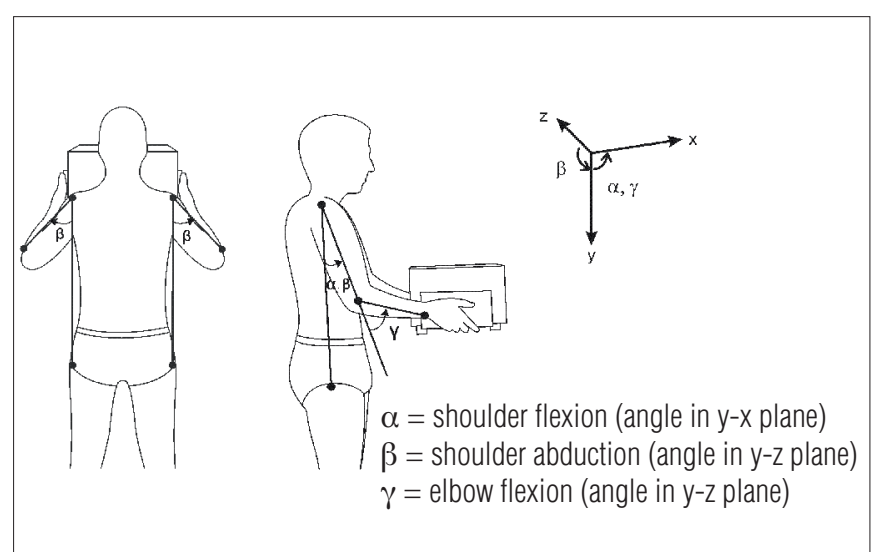

Figure 2. Illustration of the positions of the markers and coordinate system used for joint angular position calculations. 
presented as a single unit. There were also no significant differences for either EMG activity or movement (shoulder abduction) between the right and left sides and so only the results from the right side are described.

\section{EMG}

Data from APDF analysis for EMG are presented in Figure 3. The EMG was modified by both the box weight and the shelf height. Statistically significant differences was observed $(*)$ at the static $\left(10^{\text {th }}\right.$ percentile $\left.=\mathrm{P} 10\right)$, median $\left(50^{\text {th }}\right.$ percentile $=$ P50) and peak $\left(90^{\text {th }}\right.$ percentile $=$ P90 $)$ for the load levels when the box weight was increased from 7 to $15 \mathrm{~kg}$. In general, the values increased from 50 to $77 \%$ for the biceps, and from 32 to $63 \%$ for the deltoid muscle. The greatest increase occurred
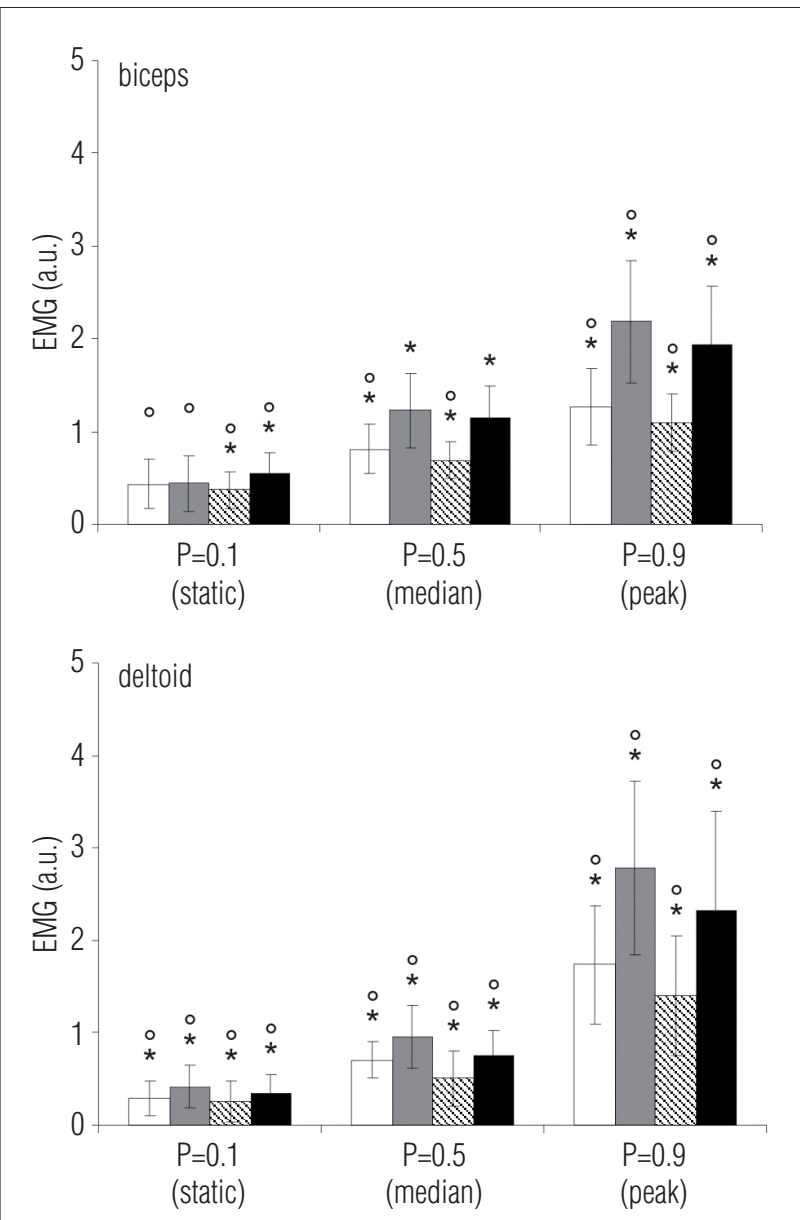
$7 \mathrm{~kg}-\mathrm{HS}$
$15 \mathrm{~kg}-\mathrm{HS}$
$\triangle 7 \mathrm{~kg}-\mathrm{LS}$
$15 \mathrm{~kg}-\mathrm{LS}$

$\left(^{*}\right)$ indicates statistically significant difference $(p<0.05)$ between 7 and $15 \mathrm{~kg}$; (o) indicates statistically significant difference $(p<0.05)$ between $\mathrm{HS}$ and LS.

Figure 3. Static, median and peak levels (mean \pm one standard deviation) of the EMG normalized to the reference condition (a.u. = arbitrary units), for the biceps and deltoid muscles of 32 subjects during manual handling of 7 and $15 \mathrm{~kg}$ boxes from the intermediate to the high shelf (HS) and from the intermediate to the low shelf (LS). at the peak load level, being between 73 and $77 \%$ (biceps) and 60 and $65 \%$ (deltoid).

EMG activity was significantly higher (o) when the box was moved to the higher shelf, compared to moving it to the lower shelf, except for the biceps at P50. At both P50 and P90, the EMG showed similar increases ( 7 to $18 \%$ higher for the biceps and 10 to $38 \%$ for the deltoid) when the box was moved to the higher shelf, compared to the lower shelf. Thus, comparatively, the deltoid presented higher activity at peak levels than the biceps.

\section{Movement}

The data from the APDF analysis for Range of Motion (ROM) are presented in Figure 4. The ROM was significantly modified by changing the height of the destination shelf, except for elbow flexion at the median load level. The ROM increase was greater when the box was moved to the higher shelf than when it was moved to the lower shelf, with the greatest increase in relation to shoulder abduction. At the static load level, the shoulder abduction increased by $7^{\circ}$ and $25^{\circ}-35^{\circ}$ at the median and peak load levels, respectively.

Changing the weight significantly changed the ROM in four of the nine situations. These significant variations ranged between 2 and $7^{\circ}$ and affected the shoulder and elbow flexion load at the static load level; shoulder abduction at the median load level; and shoulder flexion at the peak load level.

Figure 5 shows the EMG data and postural angles for a representative participant under all the conditions tested, in which the effects from changing the weight and height can be seen. The constant pattern of elbow flexion can be associated with the results observed for the $50^{\text {th }}$ percentile for this movement $(P>0.05)$.

\section{Discussion $\because:$.}

The results showed that the weight and the height influenced both movements and EMG activity. Weight changes influenced both muscular and postural behavior, but primarily muscular behavior. Higher EMG estimates for both biceps and deltoid was observed for the $15 \mathrm{~kg}$ box compared to the $7 \mathrm{~kg}$ box. The greater effort required for transferring the heavy box may explain this difference. According to Kumar ${ }^{34}$ it is possible to establish a relationship between the external load held in the hand and the muscle load. It is well established in the literature that the handling of heavy weights involves high levels of muscle activity on the lower back ${ }^{9,15}$. According to our results, the same behavior occured for upper limbs. This result corroborates the findings from Habes, Carlson and Badger ${ }^{16}$ 
who reported an increase in EMG amplitude of 150 and 94\% for the deltoid and biceps, respectively, when the weight was increased from 40 to $80 \%$ of the subject's maximal voluntary contraction (MVC).

Increasing the weight of the box also influenced movements, but to a lesser extent. Authier, Gagnon and Lortie ${ }^{35}$ reported that weight had little effect on handling techniques. They attributed their result to the small weight variation used in their experiment (from 12 to $22 \mathrm{~kg}$ ), which was insufficient to detect significant changes. Since the weight range in the present study was also small (7 to $15 \mathrm{~kg}$ ), similar tendency might have occurred.

Height changes had a clear effect on both muscular activity and postures, but mainly on the latter. In general, higher muscular activity was recorded when the box was delivered to the higher surface. This result is similar to what has been reported in the literature ${ }^{16,17,36}$. Habes, Carlson and Badger ${ }^{16}$ also found increased load on the shoulder muscles when the height of the destination surface was set at the eye level. Nielsen, Andersen and Jørgensen ${ }^{17}$ evaluated shoulder and low back muscle load by performing APDF on the trapezius and erector spinae muscles, respectively. They reported that shoulder muscular load increased when subjects lifted a $10 \mathrm{~kg}$ box from a higher surface (about $120 \mathrm{~cm}$ ), compared to lifting from lower surfaces. Anderson et al. ${ }^{36}$ reported an increase in anterior deltoid and biceps muscle activity when elevating the knuckles and elbow in a load-handling task performed with a barbell at $20 \%$ of the maximal elbow flexion force. Despite evaluating different tasks, the results summarized here agree with those reported in the present study.

When the box was lifted to the high surface, the shoulder and elbow postures presented greater amplitudes and, consequently, higher postural load. The recorded shoulder flexion and abduction at the peak load level for the high surface were around 75 and $60^{\circ}$, respectively. The most significant effect of height was observed for the shoulder abduction angle; at the peak load level, as it changed from 23 to $58^{\circ}$. On the other hand, shoulder flexion movement also presented high amplitude for the lower shelf (around 55 $5^{\circ}$ ), showing that both low as well as high surfaces generate high musculoskeletal load for shoulders. The high shoulder flexion recorded at the lower shelf handling is related to the trunk flexion as a consequence of this particular reach condition. No studies evaluating shoulder postures in handling related to low surfaces were identified in the literature, suggesting that this evidence should be considered in future studies.

The association between awkward posture and shoulder disorders is well documented in the literature ${ }^{37-39}$. The main effect of awkward postures is related to muscular load as well as to joint strain. When the arm is moved away from the body,
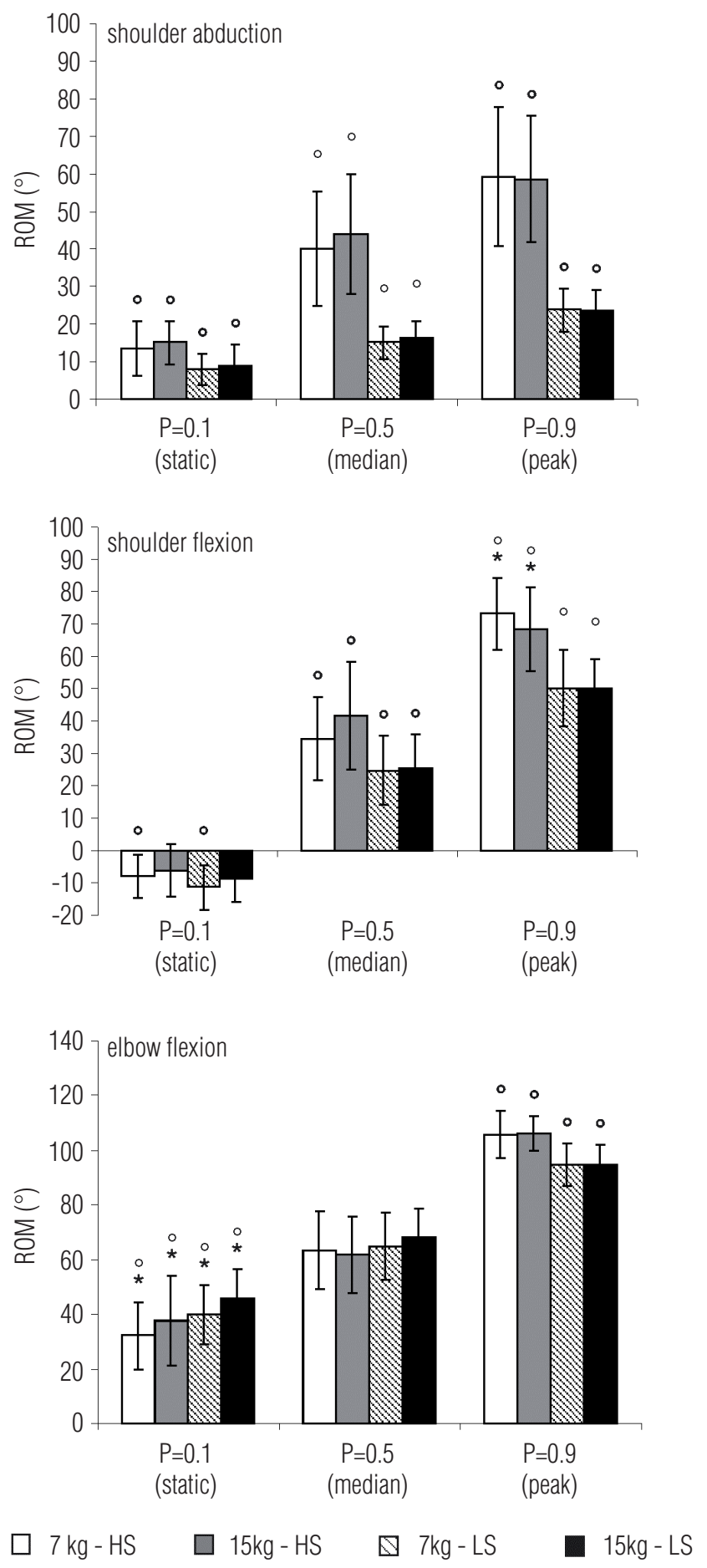

$\left(^{*}\right)$ indicates statistically significant difference $(p<0.05)$ between 7 and $15 \mathrm{~kg}$; (o) indicates statistically significant difference $(p<0.05)$ between $\mathrm{HS}$ and LS.

Figure 4. Static, median and peak levels (mean \pm one standard deviation) of range of motion (ROM) (in degrees) for right shoulder abduction and flexion and right elbow flexion, of 32 subjects during manual handling of 7 and $15 \mathrm{~kg}$ boxes from the intermediate to the high shelf (HS) and from the intermediate to the low shelf (LS). 

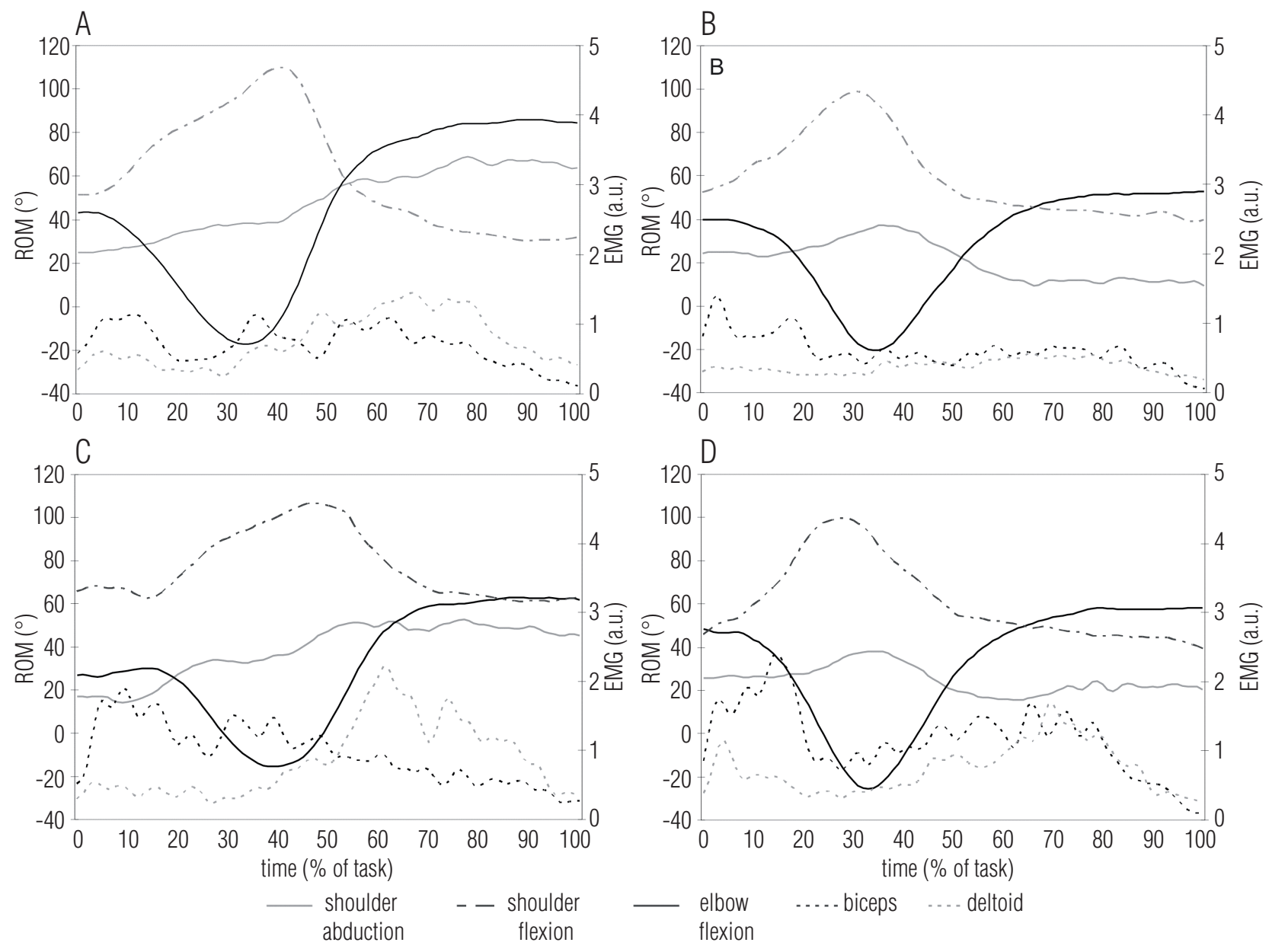

Figure 5. Time-normalized ROM (y' - angles) and EMG (y" - arbitrary units) data from right upper limb of one subject during MMH of the $7 \mathrm{~kg}$ box to high (A) and low (B) shelf and of the $15 \mathrm{~kg}$ box to high (C) and low (D) shelf.

in either the sagittal or the frontal plane, higher arm levels and internal moments are generated, thereby particularly increasing the load on the abductor muscles ${ }^{40}$. Indeed, the raised arm reduces the available space beneath the coracoacromial arch, compressing the inferior structures such as the supraspinatus and the biceps tendons, as well as the bursae. According to Ludewig and Reynolds ${ }^{41}$, most of shoulder complaints are related to occupational or athletic activities that involve frequent use of the arm at, or above, the shoulder level.

Elbow movement did not promote high loads according to the results presented here. Ranges from 80 to $120^{\circ 42}$ and 90 to $120^{\circ 43}$ have been proposed as mechanically advantageous for elbow flexion. According to Murray, Delp and Buchanan ${ }^{42}$ and Kroemer and Grandjean ${ }^{43}$, the ability to generate torque is higher within these ranges. In general, the elbow postures recorded here were within advantageous ranges.

An unexpected result was the fact that the comparison between experienced and inexperienced subjects did not show any significant difference for any of the conditions studied. Results presented by Authier, Lortie and Gagnon ${ }^{44}$ showed that experienced workers used a wide variety of grips and different strategies to carry out even a simple handling task. Even when static conditions were evaluated novice and experts showed different strategies to generate power ${ }^{20}$. Experts tend to present skillful technique than novices and these strategies positively affect body mechanics and are biomechanically more advantageous ${ }^{19,20}$. We hypothesized that our results are probably related to the weight and design of the box. The heaviest mass used for this study was $15 \mathrm{~kg}$ instead of the $22 \mathrm{~kg}$ used by Authier, Lortie and Gagnon ${ }^{44}$. Heavier loads would demonstrate different strategies more clearly. The design of the box used in the present study, presenting three supporting "feet", necessary for the load cells calibration, allowed for the subjects to grasp the box from any side, including the bottom. Thus, there was no need to move the box in order to adjust the grip. This possibility seems to have allowed the subjects to choose an interesting 
and more economical strategy for grasping the load: from the bottom. It also provided them a symmetrical grip, which generated similar load pattern to right and left sides.

The fact that subjects have preferred to grasp the box from its bottom should be better investigated in future studies due to its potential biomechanical advantage. Further studies are necessary, as well, for information about the interaction between upper limbs and spine in MMH tasks, including asymmetric handling.

\section{Conclusions $: \because \therefore$}

Mass and height variation affect both muscular activity and upper limb movements, particularly related to the shoulder. Force exertion and awkward postures decrease biomechanical advantage during handling and, consequently, are risk factors for the development of shoulder WRMSDs. The results presented here show that low heights promoted high musculoskeletal load for shoulders, since they can generate more extreme joint flexion movement. Attention should be paid to these factors when planning or redesigning a workplace. This knowledge can also be applied to plan better rehabilitation programs for MMH-related disorders, particularly focusing on return to work.

\section{Acknowledgements : :}

To Gert-Åke Hansson, of Lund University, Sweden, for discussions regarding the processing and presentation of EMG and kinematic data. The financial support from Conselho Nacional de Desenvolvimento Científico e TecnológicoCNPq (301.772/2010-0 and 142408/2009-3) and Fundação de Amparo a Pesquisa do Estado de São Paulo - FAPESP (05/53804-3).

\section{References $: \because$.}

1. Chaffin DB, Park KS. A longitudinal study of low-back pain as associated with occupational weight lifting factors. Am Ind Hyg Assoc J. 1973;34(12):513-25.

2. Ayoub MM. Problems and solutions in manual materials handling: the state of art. Ergonomics. 1992;35(7/8):713-28.

3. Straker LM. An overview of manual handling injury statistics in Western Australia. Int J Ind Ergon. 1999;24(4):357-64.

4. Yeung SS, Genaidy A, Deddens J, Alhemood A, Leung PC. Prevalence of musculoskeletal symptoms in single and multiple body regions and effects of perceived risk of injury among manual handling workers. Spine (Phila Pa 1976). 2002;27(19):2166-71.

5. Drury CG, Law CH, Pawenski CS. A survey of industrial box handling. Hum Factors. 1982;24(5):553-65.

6. Ciriello VM. The effects of box size, vertical distance, and height on lowering tasks. Int J Ind Ergon. 2001;28(2):61-7.

7. Smith DR, Wei N, Zhao L, Wang RS. Musculoskeletal complaints and psychosocial risk factors among Chinese hospital nurses. Occup Med. 2004;54(8):579-82.

8. Lusted MJ, Carasco CL, Mandryk JA, Healey S. Self reported symptoms in the neck ad upper limbs in nurses. Appl Ergon. 1996;27(6):381-7.

9. Davis KG, Marras WS. Assessment of the relationship between box weight and trunk kinematics: does a reduction in box weight necessarily correspond to a decrease in spinal loading? Hum Factors. 2000;42(2):195-208.

10. Nastasia I, Lortie M, Delisle A, Gagnon M. Perception and biomechanics data in a manual handling task: a comparative study. Ergonomics. 2007;50(12):2059-81.

11. Ciriello VM, Dempsey PG, Maikala RV, O'Brien NV. Secular changes in psychophysically determined maximum acceptable weights and forces over 20 years for male industrial workers. Ergonomics. 2008;51(5):593-601.

12. Jäger $M$, Luttmann $A$. The load on the lumbar spine during asymmetrical bi-manual materials handling. Ergonomics. 1992;35(7-8):783-805.

13. Padula RS, Coury HJCG. Sagittal trunk movements during load carrying activities: a pilot study. Int J Ind Ergon. 2003;32(3):18188.

14. Hoozemans MJ, Kingma I, de Vries WH, van Dieën JH. Effect of lifting height and load mass on low back loading. Ergonomics. 2008;51(7):1053-63.
15. Marras WS, Lavender SA, Ferguson SA, Splittstoesser RE, Yang G. Quantitative biomechanica workplace exposure measures: distribution centers. J Electromyogr Kinesiol. 2010;20(5):813-22.

16. Habes D, Carlson W, Badger D. Muscle fatigue associated with repetitive arm lifts: effects of height, weight and reach. Ergonomics. 1985;28(2):471-88.

17. Nielsen PK, Andersen L, Jørgensen K. The muscular load on the lower back and shoulders due to lifting at different lifting heights and frequencies. Appl Ergon. 1998;29(6):445-50.

18. Davis K, Marras WS. Load spatial pathway and spine loading: how does lift origin and destination influence low back response? Ergonomics. 2005;48(8):1031-46.

19. Gagnon M. Ergonomic identification and biomechanical evaluation of workers' strategies and their validation in a training situation: summary of research. Clin Biomech (Bristol, Avon). 2005;20(6):569-80

20. Chen Y-L, Lee Y-C, Chen C-J. Differences in lifting strength profiles between experienced workers and novices at various exertion heights. Int J Ind Ergon. 2011;41(1):53-8.

21. Callegari-Jacques SM. Bioestatística - princípios e aplicações. $1^{\text {st }}$ ed. Porto Alegre: Artmed; 2003.

22. Padula RS, Coury HJCG. Device for analyzing grip forces during handling. In: Premus 2004: Fifth International Scientific Conference on Prevention of Work-related Musculoskeletal Disorders Abstract Book II; 2004; Zurich; 2004, p. 599-600.

23. Freriks B, Hermens HJ. SENIAM 9: European recommendations for surface electromyography [CDroom]. Roessingh Research and Development; 1999.

24. Okunribido 00, Haslegrave CM. Pouring liquid from a pot-kinematics of an everyday task. App Ergon. 2003;34(4):355-73.

25. Barela AMF, Duarte M. Biomechanical characteristics of elderly individuals walking on land and in water. J Electromyogr Kinesiol. 2008;18(3):446-54.

26. Burden A. How should we normalize electromyograms obtained from healthy participants? What we have learned from over 25 years of research. J Electromyogr Kinesiol. 2010;20(6):1023-35.

27. Jonsson B. Measurement and evaluation of local muscular strain in the shoulder during constrained work. J Hum Ergol (Tokyo). 1982;11(1):73-88.

28. Hägg GM, Luttmann A, Jäger M. Methodologies for evaluating electromyographic field data in ergonomics. J Electromyogr Kinesiol. 2000;10(5):301-12.

29. Søgaard K, Laursen B, Jensen BR, Sjøgaard G. Dynamic loads on the upper extremities during two different floor cleaning methods. Clin Biomech (Bristol, Avon). 2001;16(10):866-79. 
30. Hansson GA, Balogh I, Ohlsson K, Granqvist L, Nordander C, Arvidsson I, et al. Physical workload in various types of work: Part I. Wrist and forearm. Int J Ind Ergon. 2009;39(1):221-33

31. Straker L, Burgess-Limerick R, Pollock C, Maslen B. The influence of desk and display design on posture and muscle activity variability whilst performing information technology tasks. Appl Ergon. 2009;40(5):852-9.

32. Mork PJ, Westgaard RH. Back posture and low back muscle activity in female computer workers: a field study. Clin Biomech (Bristol, Avon). 2009;24(2):169-75.

33. Chen $\mathrm{HC}$, Chang CM, Liu YP, Chen CY. Ergonomic risk factors for the wrists of hairdressers. Appl Ergon. 2010;41(1):98-105.

34. Kumar S. Electromyography in ergonomics. In: Kumar S, Mital A, editors. Electromyography in ergonomics. London: Taylor \& Francis; 1996. p. 1-50.

35. Authier M, Gagnon M, Lortie M. Handling techniques: the influence of weight and height for experts and novices. Int J Occup Saf Ergon. 1995;1(3):262-75.

36. Anderson AM, Meador KA, McClure LR, Makrozahopoulos D, Brooks DJ, Mirka GA. A biomechanical analysis of anterior load carriage. Ergonomics. 2007;50(2):2104-17.

37. Bernard BP. Musculoskeletal Disorders and Workplace Factors. DHHS (NIOSH) Publication
No. 97-141, US Department of Health and Human Services, Public Health Service, Centers for Disease Control and Prevention, National Institute for Occupational Safety and Health; 1997.

38. Sluiter JK, Rest KM, Frings-Dresen MH. Criteria document for evaluating the work-relatedness of upper-extremity musculoskeletal disorders. Scand J Work Environ Health. 2001;27 Suppl 1:1-102.

39. Larsson B, Søgaard K, Rosendal L. Work related neck-shoulder pain: a review on magnitude, risk factors, biochemical characteristics, clinical picture and preventive interventions. Best Pract Res Clin Rheumatol. 2007;21(3):447-63.

40. Chaffin DB, Andersson GBJ. Occupational biomechanics. $2^{\text {nd }}$ ed. USA: John Wiley \& Sons Inc.; 1991.

41. Ludewig PM, Reynolds JF. The Association of Scapular Kinematics and Glenohumeral Joint Pathologies. J Orthop Sports Phys Ther. 2009;39(2):90-104.

42. Murray WM, Delp SL, Buchanan TS. Variation of muscle moment arms with elbow and forearm position. J Biomech. 1995;28(5):513-25.

43. Kroemer KHE, Grandjean E. Fitting the task to the human: a textbook of occupational ergonomics $5^{\text {th }}$ ed. London: Taylor \& Francis; 2000.

44. Authier M, Lortie M, Gagnon M. Manual handling techniques: comparing novices and experts Int J Ind Ergon. 1996;17(5):419-29. 